Revista de Comunicación y Salud, 2020, Vol. 10, no 2, pp. 1-23

Editado por Cátedra de Comunicación y Salud

ISSN: 2173-1675

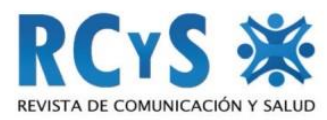

Enviado 14/08/2020

Aprobado 23/09/2020

\title{
ANÁLISIS DE LOS TITULARES Y LAS FOTOGRAFÍAS DE PORTADA EN ESPAÑA EN EL CONTEXTO DE LA CRISIS DEL CORONAVIRUS: PROTAGONISTAS, FRAMES Y LENGUAJE BÉLICO
}

\section{Analysis of the headlines and photographs of the covers in Spain in the context of the coronavirus crisis: protagonists, frames and warlike language}

\author{
José-Luis Argiñano ${ }^{1}$ \\ Universidad del País Vasco / Euskal Herriko Unibertsitatea \\ joseluis.arguinano@ehu.eus \\ Udane Goikoetxea Bilbao \\ Universidad del País Vasco / Euskal Herriko Unibertsitatea \\ udane.goikoetxea@ehu.eus
}

\section{Resumen}

Esta investigación recoge el impacto del Covid-19 en las portadas de los principales diarios generalistas de España: El País, El Mundo, La Vanguardia, y ABC y El Correo entre enero y abril. La investigación, en la que se han codificado 609 titulares y fotografías, se centra en la agenda-setting de estos diarios, los protagonistas, los frames y el análisis del discurso. La metodología seguida ha sido el análisis de contenido y del discurso, y se ha recurrido al software Nvivo para el análisis cualitativo. Los resultados muestran que los medios tratan la pandemia como una cuestión extranjera. En marzo, una vez que la crisis inunda las portadas, el marco de consecuencias sociales y sanitarias prevalece, pero con el paso del tiempo aparecen con fuerza los enfoques de soluciones y de responsabilidad. Se mantiene el protagonismo habitual de los actores gubernamentales, pero crece la exposición de la sociedad civil, especialmente en las fotografías. El recurso al lenguaje bélico actúa de agente militarizador y de domesticación de la sociedad. La estética de la pandemia se visualiza en las multi-pantallas, con especial fuerza en las protagonizadas por el Rey de España o el presidente del Gobierno. Se certifica el rol de la prensa como reconstructor simbólico de los acontecimientos, en convergencia y en tensión con el sistema político, para homogeneizar los discursos y mantener la cohesión social.

\footnotetext{
1 Jose-Luis Argiñano: Profesor en la Facultad de Ciencias Sociales y de la Comunicación de la Universidad del País Vasco/Euskal Herriko Unibertsitatea (UPV/EHU). Doctor. Tras veinte años de experiencia profesional en El Mundo, El País o 20 Minutos, desarrolla su labor investigadora en áreas vinculadas al periodismo especializado y a la seguridad alimentaria.
} 
Análisis de los titulares y las fotografías de portada en España en el contexto de la crisis del coronavirus: protagonistas, frames y lenguaje bélico

Palabras clave: Covid-19; prensa; periodismo; framing; agenda-setting; lenguaje bélico; Nvivo.

\begin{abstract}
This research reflects the impact of Covid-19 on the covers of the main generalist newspapers in Spain: El País, El Mundo, La Vanguardia, and $A B C$ and El Correo. The research, in which 609 headlines and photographs have been coded, focuses on the agenda-setting of these newspapers, the protagonists, the frames and the analysis of the discourse. The methodology followed was content analysis and Nvivo software was used for qualitative analysis. The results show that the media treats the pandemic as a foreign matter. In March, once the crisis floods the front pages, the framework of social and health consequences prevails, but with the passage of time, the frames of solutions and responsibility appear strongly. The usual role of government actors is maintained, but the exposure of civil society grows, especially in photographs. The use of warlike language acts as a militarizing agent for civil society. The aesthetics of the pandemic is visualized on multi-screens, with particular force in those featuring the King of Spain or the Prime Minister. The role of the press as a symbolic reconstructor of events is certified, in convergence and tension with the political system, to homogenize discourses and maintain the social cohesion.
\end{abstract}

Keywords: Covid-19; press; journalism; framing; agenda-setting; warlike language; Nvivo.

\title{
Cómo citar el artículo
}

Luis Argiñano, J. L. y Goikoetxea Bilbao, U. (2020). Análisis de los titulares y las fotografías de portada en España en el contexto de la crisis del coronavirus: protagonistas, frames y lenguaje bélico. Revista de Comunicación y Salud, 10 (2), 1-23. doi: https://doi.org/10.35669/rcys.2020.10(2).1-23

\section{INTRODUCCIÓN}

La expansión del covid-19 ha generado una compleja situación a nivel sanitario, económico y social. Debido al interés que las crisis generan en la ciudadanía, su presencia en la agenda temática se multiplica. Las publicaciones científicas sobre esta cuestión han conocido un crecimiento exponencial (Torres-Salinas, 2020), también en el campo del periodismo, desde distintas ópticas, como los cibermedios (LázaroRodríguez, Herrera-Viedma, 2020), las redes sociales (Cinelli, 2020) o las fake-news (Pérez-Dasilva, Meso et al., 2020).

Este tipo de información se convierte en próxima por su afección a toda la población. La situación de crisis conlleva la necesidad de información oficial, junto a las crónicas con la población civil como protagonista central. En una crisis sanitaria, las instituciones tienen que "difundir mensajes que ayuden a la población a conocer los orígenes de la 
Análisis de los titulares y las fotografías de portada en España en el contexto de la crisis del coronavirus: protagonistas, frames y lenguaje bélico

crisis, las amenazas, el nivel de alerta y las medidas a adoptar para minimizar los daños, basado frecuentemente en las apelaciones al miedo como factor persuasivo" (Rodríguez-Andrés, 2011: 33). Los periodistas buscan fuentes fiables entre los especialistas de la medicina (Lubens, 2015).

La prensa entendida como sector primordial, con los quioscos abiertos en pleno estado de emergencia, pone en valor el papel de la información. El consumo de información en situaciones de crisis sanitarias se multiplica en todos los estamentos sociales (Westlund, Ghersetti, 2015). Según datos de la Asociación para la Investigación de Medios de Comunicación AIMC (2017), la disminución del consumo en papel comenzó en 2006-2008, en el momento en que el porcentaje de consumo en la web comenzó a incrementarse. Esta situación en la carrera por la inmediatez en la web, ha generado falta de profundidad en los contenidos y ha multiplicado las posibilidades de publicar informaciones no contrastadas (Álvarez, Gurrutxaga et al. 2019). Tal y como afirma (Carr, 2011), la velocidad de las redes y las nuevas plataformas tecnológicas no son siempre aliadas de la generación de conocimiento verdadero.

Pese a este escenario, los estudios incipientes sobre la comunicación durante la pandemia apuntan al resurgimiento del protagonismo de los medios tradicionales y la reconexión a las noticias de los ciudadanos más alejados de la información (CaseroRipollés, 2020). Cabe recordar que Edelman (2020) acuñó el término medio refugio pare referirse a la necesidad que el ciudadano siente de acudir a portavoces fiables especialmente en situaciones de crisis sanitarias, que tuvo su cénit en las primeras semanas de la pandemia (Xifra, 2020). Edelman identificó los científicos, las autoridades sanitarias y los médicos como los portavoces de mayor credibilidad, por delante de los afectados y en último lugar los influencers o las celebridades. Además, basándose en encuestas confirmó que los medios de comunicación que mayor confianza inspiran son los tradicionales: prensa, televisión y radio. Esta percepción se repite en un estudio de investigadores italianos que organizó un observatorio de infodemia - propagación de noticias falsas- y confirmó que a medida que el virus se acercaba a una región los individuos que componían su sociedad demandaban más información de los medios más fiables.

Existe además literatura empírica (Castromil, 2012) que muestra cómo los temas seleccionados y los marcos asociados a los mismos por parte de la prensa en papel, lejos de quedar restringidos al ámbito exclusivo de sus lectores, desbordan estos límites alcanzando al resto de medios integrados en el mismo grupo mediático o a otros medios de diferente propiedad, extendiéndose entre los demás consumidores de información. Incluso hay evidencias (Luengo, 2014) de cómo estos contenidos, ahora digitalizados antes aún que impresos, influyen en el debate en las redes sociales. Por tanto, la prensa sirve para descifrar las pautas generales de la actividad periodística.

Esta investigación se centra en las primeras páginas de los diarios más influyentes de España. La primera página es el escaparate donde un periódico muestra su mercancía informativa y sirve para presentar de una manera rápida y directa los temas más destacados de la actualidad; define su carácter y le otorga personalidad frente a

Revista de Comunicación y Salud, 2020, Vol. 10, nº 2, pp. 1-23 
Análisis de los titulares y las fotografías de portada en España en el contexto de la crisis del coronavirus: protagonistas, frames y lenguaje bélico

los demás, es un elemento clave para ejercer ese poder de captación que el diario persigue entre la opinión pública para atraer lectores y aporta indicios claros sobre su preferencia ideológica (Davara, López et al., 2004). Los grupos mediáticos contribuyen eficazmente a uniformizar los mensajes" (Marín, Armentia et al., 2014).

A la hora de decidir qué temas se van a publicar y qué atributos se van a incluir, los periodistas se guían por criterios de noticiabilidad (Armentia, Caminos, 2009). Estos criterios son solamente parte del proceso multifactorial de la construcción de la información. Conviene en este punto remitirse a la sociología del periodismo (Shoemaker, Reese, 2013), según la cual el trabajo periodístico, la agenda-building, es el resultado del equilibrio entre fuerzas interconectadas como las rutinas laborales, el nivel empresarial, el entorno social y la ideología imperante: "Se trata de concebir las noticias como producto cultural construido colectivamente y de manera diferenciada por distintos actores sociales y factores estructurales» (Cervantes, 1996; 53).

Los medios construyen sentidos y símbolos en la presentación de la agenda política (Acosta 2013, 74). Con relación a los protagonistas, Aruguete (2009) refiere a la facilidad con la que las fuentes tradicionales obtienen la gracia de los medios para ser incluidos en todo tipo de informaciones. En cambio, el resto de la sociedad ve limitada al máximo su aparición y cuando se asoma se debe exclusivamente a actos de carácter moral o social negativos.

Obtener la atención de los medios no es baladí en tanto que "los mass-media confieren categoría, estatus, a cuestiones públicas, personas, organizaciones y movimientos sociales" (Moragas, 1985).

\section{OBJETIVOS Y PREGUNTAS DE INVESTIGACIÓN}

El objetivo principal de esta investigación es analizar las portadas de la prensa para explorar el tratamiento de las noticias surgidas en los primeros meses desde la aparición del Covid-19. Los objetivos específicos que se han planteado son los siguientes: conocer la incidencia del Covid-19 en los titulares y fotos de la prensa; examinar el tratamiento de las noticias sobre el brote del nuevo coronavirus en las portadas. Mediante la técnica del análisis de contenido se han analizado las temáticas tratadas, el encuadre, la valoración del Gobierno y sus protagonistas. También se explora el uso del lenguaje bélico.

Preguntas de investigación:

1. ¿Cuáles son las temáticas y los marcos más habituales?

2. ¿Quiénes son los protagonistas principales de los titulares y las fotografías?

3. ¿Existe el recurso al lenguaje bélico? 
Análisis de los titulares y las fotografías de portada en España en el contexto de la crisis del coronavirus: protagonistas, frames y lenguaje bélico

\section{METODOLOGÍA}

Para la muestra se han elegido cinco diarios generalistas de España ${ }^{2}$. Entre ellos, los tres de mayor difusión (El País, El Mundo, La Vanguardia), junto a $A B C$, de implantación nacional, y El Correo, adscrito a Euskadi, una de las comunidades más afectadas por el coronavirus. El criterio de inclusión de cada mancheta, aparte de su tirada, responde a su pertenencia a cada uno de los grupos mediáticos más importantes: Prisa (El País), Recoletos (El Mundo), Grupo Godó (La Vanguardia) y Grupo Correo ( $A B C$ y El Correo).

El periodo de análisis se extiende entre el 22 de enero y el 30 de abril de 2020. En esa primera fecha se publica por primera vez en la portada de uno de los diarios seleccionados información sobre el Covid. La extensión hasta el mes de abril se considera adecuada para el objetivo de analizar el impacto inicial de la pandemia en la prensa española.

El estudio se ha abordado desde una metodología cuadrangular en la que se recurre tanto al análisis del contenido, entendido este como "una técnica de investigación destinada a formular, a partir de ciertos datos, inferencias reproducibles y válidas que puedan aplicarse a su contexto" (Krippendorff, 1990:28) como a las aportaciones de la agenda setting (McCombs, Evatt, 1995), de cara a cuantificar la presencia y relevancia del Covid-19 en las primeras páginas de los diarios seleccionados; seguidamente, se recurre a la teoría del framing (Tuchman, 1983; Reese, 2001; Goffman, 2006), y, por último, al análisis del discurso (Van Dijk, 2016) para identificar los discursos beligerantes, incluso de tono bélico.

Respecto al encuadre, de las dos posibles modalidades para delimitarlo, inductiva o deductiva (De Vreese, 2005), se ha recurrido a la primera, que ofrece resultados concretos que radiografían con exactitud el tratamiento mediático sobre un tema mediante la detección de los enfoques más prominentes del objeto de estudio. Y se agrega un marco específico para las fotos, el marco de control, inducido a partir de los indicadores que proponen Entman (1993) y Tankard (2001).

Así, los encuadres seleccionados para los titulares son: consecuencias -subdividido en sanitarias, económicas y sociales- (Valkenburg, Semetko y De Vreese, 1999); el de soluciones/recomendaciones (Entman, 1993); y el de responsabilidad. Y para las fotografías se reduce a consecuencias -sanitarias y sociales-, y de control.

${ }^{2}$ EGM. Primera oleada de 2020. https://bit.ly/2YzLd51 
Análisis de los titulares y las fotografías de portada en España en el contexto de la crisis del coronavirus: protagonistas, frames y lenguaje bélico

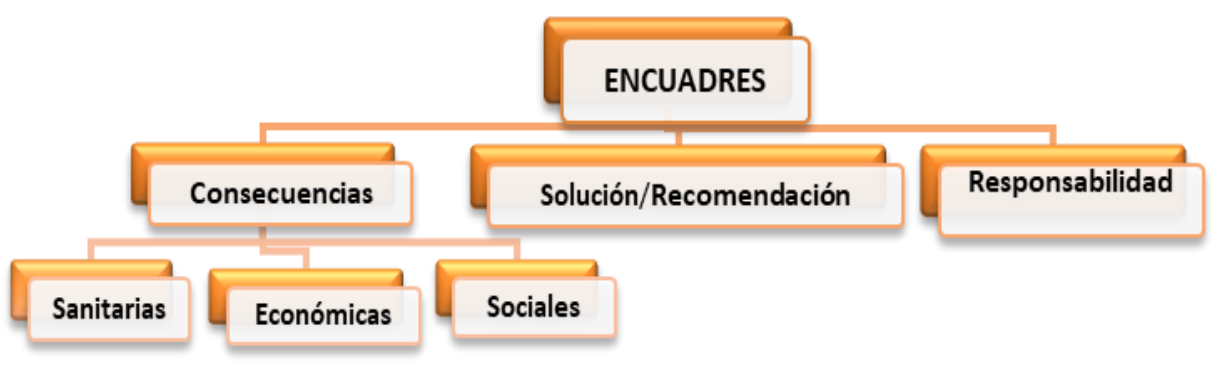

Figura 1. Tipos de encuadres noticiosos para los titulares

Fuente: elaboración propia

Las sanitarias refieren a las consecuencias que para la salud y el servicio sanitario tiene el Covid-19; económicas recoge el efecto de la pandemia en la economía, y sociales se refiere a efectos generales para toda la sociedad, como el confinamiento o la propagación del miedo. En el marco de solución y/o recomendación se codifican informaciones en las que se proponen medidas resolutivas contra el coronavirus o se ofrecen consejos útiles a la ciudadanía para afrontar la situación.

Los marcos visuales se trasmiten mediante imágenes y comparten espacio con los titulares (Scheufele, 2005; Igartua, Muñiz y Otero, 2007). En el marco de control, específico para las fotos, se encuadran imágenes con protagonistas policiales 0 militares en las que se trasmite una situación de control de la situación, vigilancia y actuación contra la pandemia. La percepción de la idea transmitida se logra a través de una comparación, sin que las fotos deban ser una réplica de la realidad (Messaris, Abraham, 2001).

Con "la intuición de que el conocimiento tiene que ser organizado en bloques" (Van Dijk, Kintsch, 1983: 47) como punto de partida, se ha procedido a diferenciar entre temas (sociedad, política y economía) y el carácter evaluativo (Igartua, Muñiz y Otero, 2007: 100). Se valora si la información es favorable, contraria o neutra a la acción del Gobierno español.

La metodología incluye también el análisis del discurso, en este caso centrado en las expresiones beligerantes, especialmente de cariz bélico, utilizadas con relación al avance de la pandemia o para dar cuenta de las medidas en contra de su propagación. Aunque la intención es ahondar en la dimensión argumentativa, más propia de géneros periodísticos como el interpretativo o la opinión, en esta investigación se codifican las noticias. Se parte de que todo texto periodístico es un acto de interpretación (Armentia y Caminos, 2009). En algunos casos estaremos ante un discurso beligerante sutil y se hará necesario llevar a cabo "la explicitación de lo implícito" (Vega, 2016: 7-10).

El estudio se completa con el análisis de contenido, una técnica, o un conjunto de técnicas que ofrece una evaluación y un análisis que tienen la virtud de la objetividad. Es una técnica de investigación sistemática y cuantitativa del contenido del manifiesto 
Análisis de los titulares y las fotografías de portada en España en el contexto de la crisis del coronavirus: protagonistas, frames y lenguaje bélico

de la comunicación, en cualquiera de sus formas (Zabaleta, 1997). Permite la inferencia de conocimientos relativos a las condiciones de producción/recepción (variables inferidas) de estos mensajes. El objetivo dominante del estudio es comunicativo y también cognitivo, a través de la explicación de procesos básico de comunicación (Gaitán y Piñuel, 1998).

El universo, que coincide con la muestra, lo componen las primeras páginas de $A B C$, El País, El Mundo, La Vanguardia y El Correo, desde el 22 de enero (día en que se publica la primera foto de portada relacionada con el coronavirus en los diarios seleccionados) hasta el 30 de abril. En este caso, la unidad de análisis será, por un lado, el titular principal de la portada y, por otro, la fotografía central de esa primera página, tanto si la imagen acompaña al titular principal como si es independiente (fotonoticia) o si acompaña a una información secundaria.

\subsection{Libro de códigos}

La definición conceptual de todas las variables y subvariables se incluyen en este denominado libro de códigos. Se han codificado:

- Nombre de la cabecera, día y mes de publicación, y formato (titular o fotografía).

- Temática (solo en titulares): Sociedad, Política y Economía.

- Ámbito geográfico: España (salvo Madrid, Cataluña y Euskadi); Madrid, Cataluña y Euskadi (se extraen de España por su protagonismo en la pandemia y porque los diarios elegidos tienen sus sedes en estos tres ámbitos); China, Italia, EEUU, Europa, Mundo (los ámbitos no incluidos en los anteriores).

- Frame: consecuencias económicas, sanitarias y sociales; responsabilidad; solución / recomendación; y otros (para titulares); y consecuencias sanitarias, sociales y de control (para fotografías).

- Valoración del Gobierno de España (solo en titulares): buena, mala, neutra y no hay (no se menciona la gestión del Ejecutivo), a partir de palabras clave, expresiones críticas o enaltecedoras, etc.

- Protagonista: autonómico: Los siguientes deben aparecer de forma textual: Sánchez, Torra, Urkullu y Casado; Gobierno (de España) Rey de España, Papa, OMS y Mobile; China (Gobierno de China), económico (asociaciones patronales, pymes, Bolsa, banca, FMI), Ejército, europeo (gobiernos o instituciones europeas y sus portavoces), gubernamental (ministros de España y gobiernos autonómicos y sus portavoces), médico-científico, Policías (todos los cuerpos policiales de España), sociedad civil (ciudadanos solos o agrupados).

- Términos o expresiones bélicas o violentas. Se distinguen tres categorías: término bélico (palabras o expresiones que según el DRAE tienen algún significado propio del campo semántico militar o bélico); término adaptado (procedentes de otros campos ajenos al militar -deportivo, sanitario, económico, etc.-, que contienen una carga violenta); metáfora violenta (expresiones metafóricas que contienen un significado violento) (Barrero, 2007).

Revista de Comunicación y Salud, 2020, Vol. 10, nº 2, pp. 1-23 
Análisis de los titulares y las fotografías de portada en España en el contexto de la crisis del coronavirus: protagonistas, frames y lenguaje bélico

La elaboración del libro de códigos y la codificación se ha llevado a cabo por los dos firmantes del artículo. Utilizando el programa SPSS, la codificación se ha certificado con el coeficiente kappa de Cohen (0.71), y se ha comprobado, con el chi cuadrado, la existencia de diferencias estadísticamente significativas entre las variables.

\section{RESULTADOS}

Respecto a la evolución de los titulares a lo largo del periodo analizado, constatamos que la primera referencia al Covid-19 en las primeras páginas de los cinco grandes diarios españoles aparece el 21 de enero en El País: "Las claves del virus letal que se expande por Asia". El titular apenas se asoma en los sumarios, en la parte superior, encima de la cabecera. Un día más tarde el mismo diario repite la acción, en el mismo espacio. En esta ocasión, por primera vez en la prensa española analizada, se nombra al "coronavirus", pero se añade "de Wuham", y se advierte que "desborda a China" y que "llega a EEUU". Ese mismo día, El Correo lleva a su primera página la fotografía principal de Wuham. Cronológicamente, es la primera unidad de análisis de esta investigación. El primer titular principal en portada no aparece hasta dos días más tarde, el 24 de enero, en El País: "China aísla a 21 millones de personas para frenar la expansión del virus". A partir de ahí los titulares sobre el coronavirus han ido in crescendo, en relación directamente proporcional a la presencia del virus en el Estado. En abril la pandemia es portada todos los días en los cinco grandes diarios.

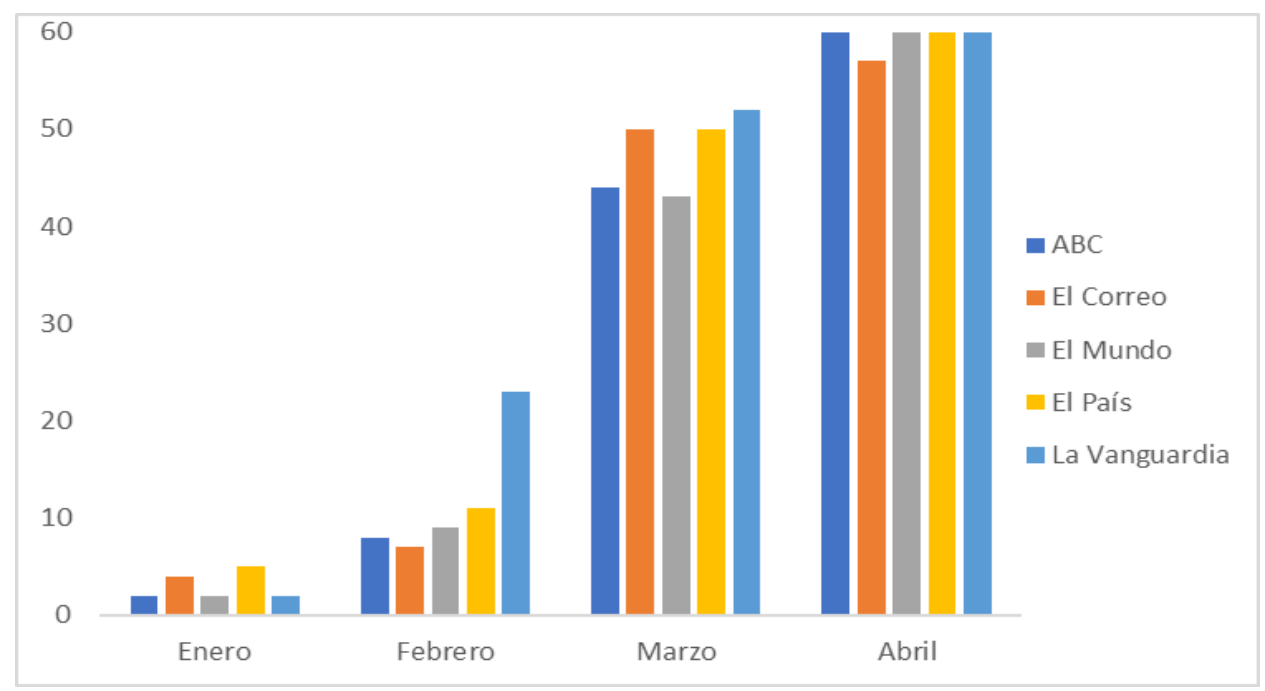

Figura 2. Evolución mensual del número de titulares y fotos de portada Fuente: elaboración propia

Desde febrero hasta el 31 de marzo se han publicado 319 titulares y 290 fotografías principales en las portadas de los cinco diarios elegidos. El más prolífico es $\mathrm{La}$ Vanguardia (137), seguido de El País (126) y El Correo (118). La última posición, empatados, es para ABC y El Mundo (114). 
Análisis de los titulares y las fotografías de portada en España en el contexto de la crisis del coronavirus: protagonistas, frames y lenguaje bélico

En enero las apariciones fueron sólo 15, para subir a 58 en febrero y a 239 en marzo en que casi todos los días el tema y la foto principal refieren al coronavirus. Abril (297) marca un hito periodístico con 297 casos, ya que el coronavirus ocupa todos los titulares y foto principales de las portadas de los cinco grandes diarios españoles, salvo en un caso, el 30 de abril. Ese día El Correo, sin olvidar su carácter local, publica una foto que refiere al homicidio en Bilbao de un anciano a manos de otro hombre de 81 años.

El volumen de publicación de informaciones en enero es menor y resulta insuficiente para realizar valoraciones cuantitativas sobre la actitud informativa de la prensa con relación al coronavirus. En cambio, resulta significativo que de las 15 informaciones solo dos, en El Correo, estén focalizadas en España y, en concreto, en Euskadi. La prensa española en enero entiende que se trata de una cuestión ajena, localizada en China, y así se expresa en los titulares y fotos aludiendo a "virus chino", "coronavirus chino".

Esta dinámica se mantiene en febrero, pero con menos fuerza. En este mes, la prensa sigue presentando el coronavirus como una cuestión extranjera, de China o de Italia, y más adelante como un problema mundial, a causa de los mensajes de alerta emitidos por la Organización Mundial de la Salud (OMS). Comienza a aparecer el ámbito geográfico España, especialmente Cataluña.

Los datos de febrero son suficientes en número para realizar un primer análisis comparativo fiable de las estrategias de las cinco cabeceras. Resulta evidente que $\mathrm{La}$ Vanguardia (23 informaciones) vislumbró antes que la competencia la importancia de la pandemia, muy por delante de El País (11), El Mundo (9) y $A B C$ (8). La preeminencia a la información local que imprime El Correo (7) le sitúa en este caso en última posición.

La primera posición de La Vanguardia se sustenta en informaciones internacionales y, también, localizadas en Cataluña. En este último caso, las noticias recogen la suspensión de Mobile, la feria de tecnología móvil de relevancia mundial: "El Mobile trata de atajar más bajas de empresas por la crisis del coronavirus" (6/2/2020).

Entre el resto de los diarios, solo a El País le pareció el tema merecedor del titular principal, aunque para cuestionar su suspensión: "El Gobierno y la OMS ponen en cuestión el cierre de Mobile" (14/2/2020). El cariz eminentemente económico, e incluso geoestratégico, de Mobile se certifica con el titular también en El País dos días después: "EEUU exige a Europa que se una a su guerra tecnológica contra China". La noticia se refiere al potencial del gigante asiático en especial en el área de la tecnología de telefonía móvil, y cuyas últimas novedades se presentan cada año en Mobile. En ese momento la prensa permanece ajena al potencial peligro del coronavirus y lleva a portada, en este caso al pie de foto de portada, un texto en el que, por un lado, se subraya que ya se han computado más de 2.000 muertos en China y, por otro, que "pese a que el virus aún no está contenido, la OMS aseguró ayer que se han hecho grandes progresos" (La Vanguardia, 20/2/2020). En marzo el número de piezas de análisis se acercan a 50 (fotos y titulares) para cada uno de los medios. Este mes se

Revista de Comunicación y Salud, 2020, Vol. 10, nº 2, pp. 1-23 
Análisis de los titulares y las fotografías de portada en España en el contexto de la crisis del coronavirus: protagonistas, frames y lenguaje bélico

menciona, por primera vez, la vacuna contra el Covid-19. El Mundo es el primer medio en citarla, en una pieza en la que se recoge la advertencia de la OMS de que la vacuna no estará lista al menos hasta finales de 2021. Y en abril ya se ha mencionado que, salvo una foto, el resto de las imágenes y titulares principales se refieren al coronavirus.

\section{1. Ámbito geográfico}

El ámbito geográfico se ha codificado tanto en titulares como en fotografías. El principal ámbito al que se circunscriben los titulares y fotos es España, seguida de Euskadi, Madrid y Mundo. Esa primera posición se afianza con el elevado porcentaje en $A B C$ (76,3\% de sus titulares y fotos), por encima de El Mundo, (72,8\%). El País (62,2\%) limita mucho más la reiteración de este ámbito, y La Vanguardia $(51,8)$ y, especialmente, El Correo $(23,7 \%)$ muestran su carácter de diario periférico con esta variable.

Señalaremos que en marzo hay un cambio de tendencia radical que convierte a España en el principal ámbito. Ese mes abarca más de la mitad de las codificaciones, al igual que en abril. También es importante la presencia de los ámbitos Cataluña y Euskadi, aunque se reduce a los diarios La Vanguardia y El Correo, respectivamente, de la misma forma que Madrid se limita a El País, El Mundo y $A B C$. En general los ámbitos más lejanos, como China, Mundo o Italia pierden peso en la línea del tiempo a favor de España y también de Europa. Cataluña muestra altibajos, condicionada por la importancia de la feria Mobile en febrero. Euskadi muestra una línea homogénea, fruto del interés permanente que El Correo dedica a esta comunidad a lo largo de toda la crisis.

\subsection{Temáticas y protagonistas}

La temática solo se ha codificado en los titulares. Más de la mitad se encuadran en Sociedad (168), muy por delante de Economía (86). El tercer lugar queda para Política (65), por ejemplo: "Los presidentes autonómicos cierran filas con el Gobierno" (El País, 16/3/2020). Pero la tendencia muestra que los enfoques políticos se fortalecen en abril, mientras que las temáticas sociales pierden peso en la línea del tiempo. Los titulares que dan cuenta de cuestiones económicas mantienen una tendencia creciente uniforme.

El cruce de las variables del ámbito geográfico y la temática permite averiguar que el enfoque político se multiplica cuando la noticia se localiza en España (son el 81,5\% de todas las informaciones de política). En Europa y en Cataluña el enfoque es más económico: "Bruselas propone un fondo contra la crisis de 1,6 billones" (El País, 23/4/2020), en contraste con Euskadi, más social.

En lo referente a los protagonistas de la información, constatamos que el actor principal de los titulares es la sociedad civil (26,33\%): "Un turista alemán en La Gomera, primer caso de coronavirus confirmado en España" (El Correo, 1/02/2020); "Alerta máxima en Italia tras 75 contagios de coronavirus y dos muertos (El País, 23/02/2020); "Un vizcaíno, primer muerto en Euskadi" (El Correo, 5/03/2020). El segundo lugar lo

Revista de Comunicación y Salud, 2020, Vol. 10, nº 2, pp. 1-23 
Análisis de los titulares y las fotografías de portada en España en el contexto de la crisis del coronavirus: protagonistas, frames y lenguaje bélico

ocupan los políticos (20,68\%). Entre ellos, el presidente del Gobierno (16,61\%), en primer lugar. La prensa en la que más aparece Sánchez es El Mundo, con un 4,39\%, seguido de $A B C$ con un 3,45\% y El País y La Vanguardia, con un 3,13\% en ambos. El primer titular que recoge a Sánchez como protagonista principal es de marzo: "Sánchez anuncia 'semanas difíciles'" y ayudas para familias y empresas" (El País, 11/03/2020); "Sánchez dosifica la respuesta al virus pese a la emergencia económica" (El Mundo, 13/03/2020). El siguiente personaje político con más exposiciones es Casado $(2,19 \%)$. $A B C$ es con diferencia la publicación en la que más aparece, con un $1,25 \%$, seguido por El Mundo, con un $0,94 \%$. En el resto de los medios no aparece. El tercer y cuarto lugar los ocupan los presidentes de las autonomías vasca y catalana. Urkullu con un 1,25\%, aparece solamente en El Correo: "Urkullu plantea que los niños puedan salir y que el comercio abra a partir del día 26" (El Correo, 18/04/2020); Torra, por el contrario, aunque con menos presencia, 0,63\%, aparece tanto en El País como en La Vanguardia con un $0,31 \%$ en ambos: "Torra busca reforzar el independentismo durante la crisis" ( $E I$ País, 18/04/2020); "Torra esgrime un informe demoledor para insistir en más confinamiento" (La Vanguardia, 26/03/2020).

Las referencias al Gobierno (10,66\%) y otras cuestiones gubernamentales (7,84\%) ocupan el $18,50 \%$ de la información. En información sobre el Gobierno y lo gubernamental destaca El Mundo con un 5,64\%. "Iglesias divide el Gobierno al exhibir su poder ante Escrivá" (El Mundo, 17/04/2020); "El caos de datos siembra dudas sobre el fin del confinamiento" (El Mundo, 18/04/2020). En segundo lugar, está El País con un 3,76\%: "El gobierno lanza un plan para proteger a los sectores más vulnerables" (EI País, 1/04/2020); "Sanidad: "La desescalada la dirige el Gobierno"” (El País, 25/04/2020). El resto se coloca por debajo del $3 \%$.

La economía es el siguiente asunto informativo, ya que en general ocupa el 10,97\% del total. El contenido referido a aspectos económicos aparece con una frecuencia de 4,08\% tanto en El País como en La Vanguardia: "La expansión del coronavirus aleja la recuperación de la economía" (El País, 29/02/2020); "La amenaza de un parón económico por el virus hunde las bolsas" (La Vanguardia, 28/02/2020). Hay que subrayar que en el caso de El Correo este aspecto aparece unido a lo que hemos denominado sociedad civil, ya que hace alusiones a las consecuencias económicas: "Más de 51.000 trabajadores vascos se han visto afectados por regulaciones de empleo" (El Correo, 24/03/2020); "Euskadi encara la fase dura del confinamiento con una parálisis total de la industria" (El Correo, 30/03/2020).

Otro de los protagonistas de las noticias analizadas en los primeros cuatro meses del presente año, es el sector médico científico con un 9,69\%: La presencia de los sanitarios crece de manera sustancial sobre todo a partir de mediados de marzo: "iGracias!" (El Correo, 23/03/2020); "El virus diezma a los sanitarios por el retraso en la protección" (El Mundo, 25/03/2020). En este sentido, tenemos que subrayar que los q más alusiones hacen a este tipo de protagonistas son el $A B C$ con un $1,57 \%$ y El Correo con 1,25\%. Por el contrario, esta información aparece solo en un $0,31 \%$ en $\mathrm{La}$ Vanguardia. Aunque podemos encontrar a los protagonistas de la salud en los titulares, su presencia es muy destacada en las fotografías.

Revista de Comunicación y Salud, 2020, Vol. 10, nº 2, pp. 1-23 
Análisis de los titulares y las fotografías de portada en España en el contexto de la crisis del coronavirus: protagonistas, frames y lenguaje bélico

\subsection{Encuadres}

En el contexto de los frames analizados en los titulares señalaremos que la relación entre los personajes protagonistas es mayoritaria respecto a la sociedad civil, ya que presenta los valores más altos en cuanto a su relación a las consecuencias sanitarias y sociales, un $10,34 \%$ en ambos. También es importante su relación con las consecuencias económicas en un 3,13\% y con las soluciones-recomendaciones en un $2,19 \%$.

Respecto al Gobierno y lo gubernamental está aparece relacionado con las consecuencias sociales en un $5,64 \%$ y con las soluciones y recomendaciones en un $4,44 \%$. Las consecuencias económicas tienen también importancia ya que aparecen relacionadas en un $4,39 \%$.

Con relación a los frames los más habituales se refieren a las consecuencias, sobresaliendo las sociales $(28,21 \%)$, por delante de las consecuencias económicas $(23,20 \%)$ y las sanitarias $(21,63 \%)$. La cuarta posición es para el marco de soluciones/recomendaciones (19,44\%) y en quinto lugar, aparecen los enfoques de responsabilidad $(6,90 \%)$. El resto se ha codificado en Otros.

El predominio del enfoque de consecuencias sociales se debe a la atención que los medios dedican a cuestiones sobre la sociedad civil, empezando por China ya en enero: "Los españoles evacuados de Wuhan quedarán en cuarentena en su destino" ( $E l$ País, 29/01/2020); En febrero, el foco sigue estando en la sociedad china e italiana: "Rusia prohíbe la entrada de chinos por el coronavirus" (La Vanguardia, 19/02/2020); "Codogno, ciudad fantasma" ( $A B C, 23 / 02 / 2020)$; "El norte de Italia cierra las escuelas y cancela los actos públicos por el virus" (El País, 24/02/2020); También aparecen ya informaciones de la OMS como tema principal: "La OMS teme turbulencias sociales por el coronavirus" (La Vanguardia, 23/02/2020) y también como consecuencia sanitaria: "La OMS pide al mundo que se prepara para una pandemia" (El País, 25/02/2020). La figura 4 indica la evolución de los frames en el periodo analizado. 
Análisis de los titulares y las fotografías de portada en España en el contexto de la crisis del coronavirus: protagonistas, frames y lenguaje bélico

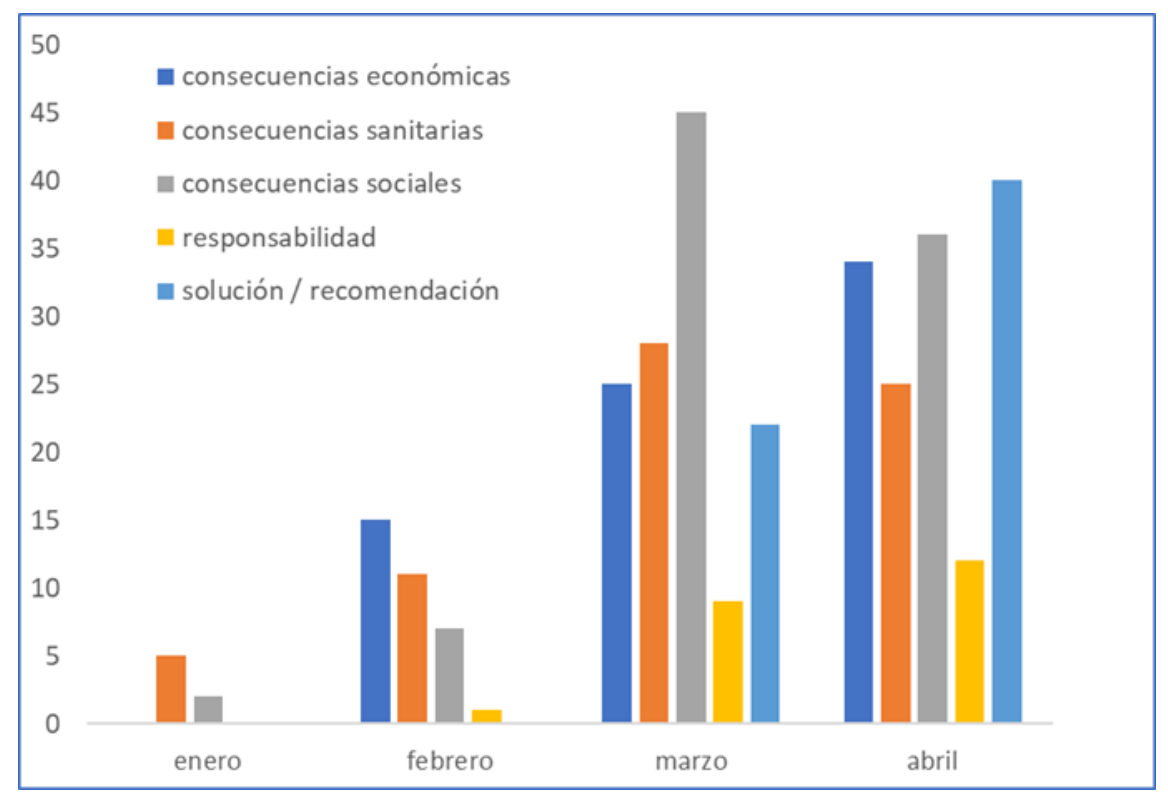

Figura 3. Evolución de los frames en los titulares. En valores absolutos. Fuente: elaboración propia

Las consecuencias económicas $(23,20)$ son el segundo frame más manido y aumentan con el tiempo. Su presencia al inicio del periodo estudiado obedece a la mirada internacional: "La epidemia del coronavirus amenaza la economía mundial" ( $\mathrm{La}$ Vanguardia, 3/02/2020); "El Mobile trata de atajar más bajas de empresas por la crisis del coronavirus" (La Vanguardia, 6/02/2020); "El salto a Italia del coronavirus contagia a las bolsas mundiales" (La Vanguardia, 25/02/2020); "El coronavirus provoca la peor semana de la bolsa en 10 años" (El Mundo, 29/02/2020). Y también nacional sobre todo a partir de marzo: "El Gobierno y la OMS ponen en cuestión el cierre de Mobile" (EI País, 14/02/2020); "El Gobierno facilita el cierre de empresas por riesgo de contagio" (El Mundo, 5/03/2020); "El coronavirus cuesta ya a la bolsa española 110.000 millones" (EI País, 7/03/2020).

El marco de consecuencias sanitarias $(21,63 \%)$ lo encontramos en Euskadi el primer mes del año "Alerta en Euskadi al detectarse un posible caso de coronavirus chino en Cruces" (El Correo, 25/10/2020); "Osakidetza se mantiene en guardia pese al negativo del coronavirus en Cruces" (El Correo, 26/10/2020) Y paralelamente a nivel mundial: "La OMS declara la emergencia mundial ante la expansión del virus (El País, 31/01/2020). Su presencia aumenta, sobre todo en El Correo, en marzo y casi se mantiene en abril.

Los enfoques de solución/recomendación $(19,44 \%)$ no son muy significativos. La mayoría aparecen en El País. El Correo y El Mundo empatan: "Europa promete 25.000 millones contra la "tormenta" del coronavirus" (El Mundo, 11/03/2020); "La UE activa un plan inmediato de 7.500 millones " (La Vanguardia, 11/03/2020); "La sanidad madrileña cierra filas ante la emergencia" ( $A B C, 13 / 03 / 2020)$; "El Gobierno recomienda ahora el uso de mascarillas en la calle" (El Mundo, 4/04/2020). 
Análisis de los titulares y las fotografías de portada en España en el contexto de la crisis del coronavirus: protagonistas, frames y lenguaje bélico

Respecto a los titulares en los que destaca el marco de responsabilidad $(6,90 \%)$ la mayoría los encontramos en el $A B C$. "Estado de confusión" ( $A B C, 14 / 03 / 2020)$; "Los test son claves para la curva pero sólo nos falta que el Estado nos dé el material" ( $A B C$ 22/03/2020); "El Gobierno ya lo sabía" ( $A B C, 26 / 03 / 2020)$; "Sánchez elige parar la economía” ( $A B C$ 29/03/2020).

Constatamos que el presidente del Gobierno, Sánchez, aparece relacionado con consecuencias económicas y solución-recomendación con el mismo dato, 4,39\% pero sobre todo con consecuencias sociales en un $5,33 \%$. Subrayaremos que la relación con las consecuencias sanitarias es sólo del $0,94 \%$. Con referencia al representante de la oposición, aparece relacionado con los contenidos sobre responsabilidad y con los que hacen referencia a soluciones y recomendaciones con un $0,94 \%$ en ambos. Hay que subrayar que la relación con las consecuencias sociales $0,31 \%$ y que no aparece relacionado ni con las consecuencias económicas ni con las sanitarias. El presidente del Gobierno Vasco se relaciona sobre todo con las consecuencias sociales en un $0,63 \%$, pero también con las consecuencias sanitarias en un $0,31 \%$ y con las soluciones y recomendaciones en el mismo porcentaje. El presidente de Cataluña aparece relacionado con las soluciones y recomendaciones en un $0,31 \%$.

Dentro de la variable de la valoración del Gobierno español, se ha analizado si la información -su acción- se estima como buena, mala o neutra.

En los 319 titulares analizados constatamos que en más de la mitad de las noticias $(53,29 \%)$ no hay ninguna valoración de la labor del Ejecutivo. El análisis de esta variable se ha llevada a cabo con las restantes noticias. La valoración neutra $(22,57 \%)$ y mala $(21,32 \%)$ - sube en abril y se dispara en mayo-, presentan datos similares en el resto. La valoración buena es de un 2,82\%: "Los presidentes autonómicos cierran filas con el Gobierno" (El País, 16/03/2020); "Michel: "¿Tenemos acuerdo, Pedro?". Sánchez: "así es imposible"' (El País, 23/02/2020). Destaca que en el El País no se ha encontrado ninguna lectura negativa de la labor del Gobierno. Le siguen El Correo y $\mathrm{La}$ Vanguardia en informaciones acríticas; solo el 1,25\% son negativas: "El reparto de mascarillas en el transporte enfrenta a los gobiernos central y vasco" (El Correo, 12/04/2020); "Las indecisiones del Gobierno marcan el parón de la economía" ( $\mathrm{La}$ Vanguardia, 31/03/2020). En el lado opuesto, El Mundo (10,03\%) y el diario $A B C$ $(8,78 \%)$ son los que valoran más negativamente la acción del Gobierno: "Alarma en diferido" (El Mundo, 14/03/2020); "Sánchez extiende la alarma entre críticas a su gestión" ( $E$ l Mundo, 23/03/2020); "Atrincherados ante la semana más trágica" ( $A B C$, 23/03/2020).

\subsection{Lenguaje bélico}

La nube de palabras -realizada con el software Nvivo12- visualiza la preeminencia de la palabra Gobierno en los titulares de los cinco diarios de mayor difusión en España. El protagonismo de los organismos oficiales en los mass media es intenso en medio de la 
Análisis de los titulares y las fotografías de portada en España en el contexto de la crisis del coronavirus: protagonistas, frames y lenguaje bélico

pandemia, por encima del término coronavirus o virus. La reiteración del término Sánchez multiplica la presencia institucional en los titulares.

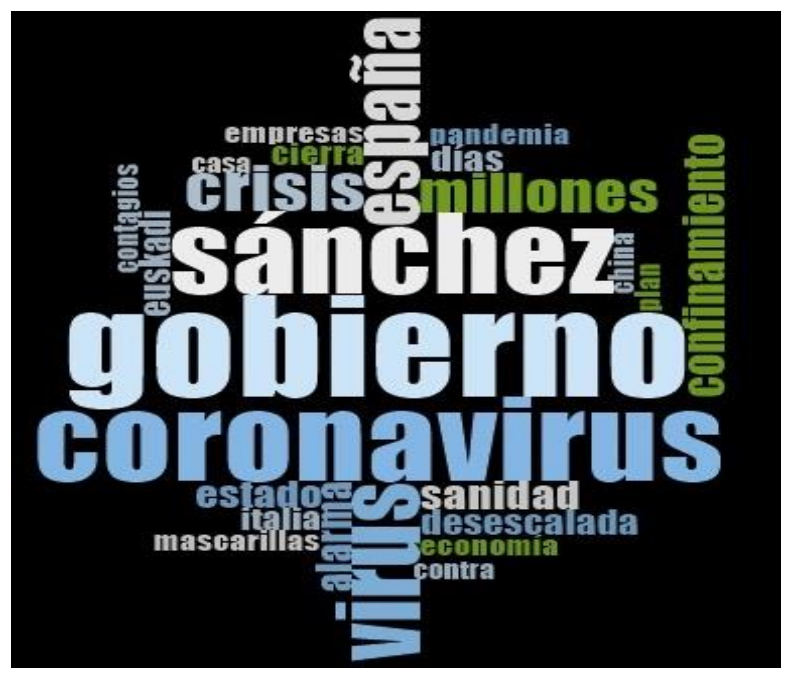

Figura 4. Palabras más comunes en los titulares. El tamaño representa el porcentaje de apariciones.

Fuente: elaboración propia

Los términos como millones o empresas, más visibles que confinamiento o sanidad, reflejan que los titulares sobre la pandemia trascienden la información sanitaria y se extienden con fuerza al ámbito económico. Desescalada aparece menguada, pero es evidente que el término está condicionado porque el periodo de estudio tiene el límite del 30 de abril. Observamos que ninguno de los términos del gráfico está impregnado con el cariz del lenguaje bélico, aunque confinamiento refiere a situaciones que se viven en las guerras.

No obstante, el lenguaje bélico está presente de forma explícita en 28 informaciones -titulares más el texto de acompañamiento- de las primeras páginas analizadas. Supone un porcentaje de casi un $9 \%$ en una muestra de 319 unidades. Es un número reseñable, teniendo en cuenta la trascendencia que tienen las portadas. Los términos bélicos (13) son el recurso más utilizado, entre los tres definidos en la metodología, por encima de las metáforas violentas (11). Los términos adaptados (4) son significativamente menos. El Mundo y $A B C$ son los diarios más activos en la utilización de todos estos recursos. El Correo es, por el contrario, el más reacio a su uso en los titulares.

Con términos bélicos se recogen palabras o frases que contienen un significado marcial en alguna de las acepciones del diccionario de la Real Academia Española (RAE). Se han localizado casos en los que el sintagma nominal incluye de forma textual la palabra guerra: "El Ramón y Cajal es un hospital en guerra"” (El Mundo, 21/3/2020); "Es la guerra de nuestra generación" (El País, 22/3/2020); incluso con el término de sujeto de la oración: "Una guerra, casa por casa" ( $A B C, 13 / 4 / 2020)$. Existen términos 
Análisis de los titulares y las fotografías de portada en España en el contexto de la crisis del coronavirus: protagonistas, frames y lenguaje bélico

que entrañan una acción violenta: "Ofensiva para evitar nuevos contagios entre el personal sanitarios" (La Vanguardia, 4/3/2020); "El presidente Xi Jimping dijo que imponerse al virus es una prueba clave del sistema de China" (El País, 5/2/2020). Y, en contraste, otros términos no conllevan una acción explícita, sino que son más neutrales, o de carácter defensivo: "Los presidentes autonómicos cierran filas con el Gobierno" ( $E$ I País, 16/3/2020); "España no se rinde" ( $A B C, 19 / 3 / 2020)$; "Atrincherados ante la semana más trágica" $(A B C, 23 / 3 / 2020)$.

Las metáforas utilizadas carecen de cariz militar, contienen un significado amenazante: "El Ibex 35 pierde 20.900 millones en un 'lunes negro" ( $A B C, 25 / 2 / 2020)$; "Milán vive presa del pánico" (El Correo, 27/2/2020); "45 días de imprevisión y pasividad que permitieron el zarpazo del virus" (El Mundo, 22/3/2020). "Han jugado a la ruleta rusa'" (El Mundo, 24/4/2020).

La tercera figura retórica empleada es el término adaptado. En los ejemplos se comprueba que no hay relación directa con la violencia pero sí intrínseca, con el objetivo de generar interés a partir de la relación entre el término y el suspense, es decir, el miedo, que no deja de ser una forma de violencia: "Codogno, ciudad fantasma" $(A B C, 23 / 2 / 2020)$; "Sanidad considera Vitoria 'zona caliente'" (El Correo, 3/3/2020); "Objetivo: reflotar la imagen de España en el exterior" ( $A B C, 30 / 4 / 2020)$. Este último ejemplo da por sentado que España es un país hundido y por lo tanto necesita ser "reflotado". Con esta metáfora se traslada una imagen calamitosa del país mientras se depositan las esperanzas en los actores de la información, los Reyes de España, en conversación vía multi-pantalla con los deportistas Rafael Nadal, Fernando Alonso y Pau Gasol.

\subsection{Fotografías}

Resulta significativo que casi la totalidad de las noticias en las que el actante es la sociedad civil el marco corresponde a las consecuencias sociales. Esta inercia se repite cuando se trata de los médicos, sanitarios o científicos como protagonistas y del marco de las consecuencias sanitarias.

Las imágenes habituales de la sociedad civil en las portadas actúan de contraste a las hard news que han copado los titulares durante la pandemia. Son imágenes de ciudadanos saludando a la cámara desde sus balcones y en el interior de sus pisos asimilando nuevas rutinas. En otros casos son escenas de calles casi desérticas que trasmiten desasosiego y que incrementan la dureza de la portada.

El enfoque visual de consecuencias sanitarias refiere a las víctimas de la pandemia, en muchos incluyendo fallecidos. La tragedia se intensifica con el uso del blanco y negro en la fotografía $(A B C, 13 / 4 / 2020)$. El lado positivo aparece en las imágenes que enseñan las muestras de solidaridad hacia este colectivo. O los propios médicos y sanitarios aplaudiendo. Son foto que refuerzan el sentimiento de solidaridad y la sensación de comunidad, un efecto inherente a los medios de comunicación. 
Análisis de los titulares y las fotografías de portada en España en el contexto de la crisis del coronavirus: protagonistas, frames y lenguaje bélico

Las policías y el Ejército, sumados ambos, son el tercer tipo de actor más presente en las fotografías de portada. La pandemia ha otorgado a ambos un protagonismo preferente. En las imágenes, muestran una actitud proactiva, aportan sensación de seguridad y control, tanto en la vigilancia como en labores sanitarias. Las tanquetas militares en el aeropuerto de Bilbao o en Montjuic, reflejadas en las portadas de los principales diarios españoles, revelan la transformación de la vida diaria que ha traído el Covid-19. Se puede sumar a este conjunto la imagen del rey vestido de militar, con mascarilla y guantes $(A B C, 4 / 4 / 2020)$. El titular que acompaña a la imagen dice así: "Fortaleza para seguir confinados por decreto". La fortaleza y el confinamiento por decreto se desplazan a la metáfora que supone la figura marcial del Rey como personificación del control. La figura de Sánchez, en cambio, presenta más variaciones, y aunque el marco de responsabilidad es mayoritario, también aparecen enfoques de consecuencias sociales y, en menor medida, de solución /recomendación.

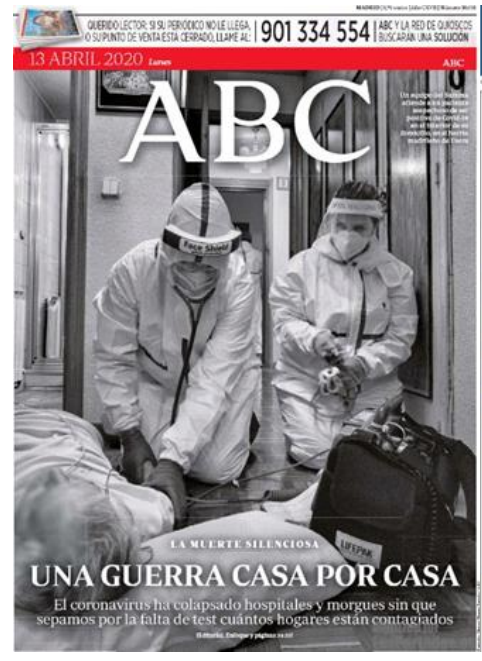

\section{LAVANGUARDIA}

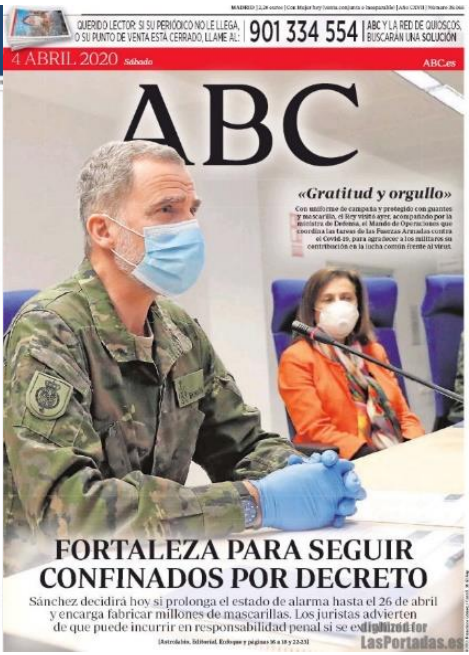

Figura 5. Portadas de ABC y La Vanguardia (2020)

Fuente: elaboración propia

\section{DISCUSIÓN Y CONCLUSIONES}

El brote del covid-19 ha entrañado un reconocimiento del periodismo como una instancia esencial en las sociedades del siglo XXI (Casero-Ripollés, 2020). Asimismo, los datos permiten afirmar que la primera página es el escaparate donde un periódico muestra su mercancía informativa y sirve para presentar de una manera rápida y directa los temas más destacados de la actualidad (Davara et al., 2004).

Si se establece una clasificación, La Vanguardia se adelanta a la competencia en calibrar la importancia de la pandemia. Las más rezagada es la prensa conservadora, $A B C$ y El Mundo. En un primer momento el Covid-19 se trata como un tema extranjero, pero La Vanguardia enseña un interés especial por acercar lo global a lo local informando, primero, desde China, y después desde Italia. La línea del tiempo enseña que en marzo y abril la información se localiza en España, especialmente en ABC, y es 
Análisis de los titulares y las fotografías de portada en España en el contexto de la crisis del coronavirus: protagonistas, frames y lenguaje bélico

en este ámbito en el que se publican las noticias más críticas con el Gobierno. Paralelamente, la temática social se debilita, y el económico se mantiene en el tiempo.

En consonancia con la temática, es mayoritario el enfoque de consecuencias sociales, ligado al confinamiento o la propagación del miedo. Pero el frame de consecuencias económicas, en segundo lugar, desvela la importancia que los medios otorgan al funcionamiento del sistema económico por encima de las consecuencias sanitarias. El marco de solución/recomendación, algo más minoritario, propugna la adopción de medidas en contra de las consecuencias negativas de la pandemia, y beneficia así la imagen de los gobiernos, mientras que, por el contrario, el enfoque de responsabilidad, especialmente habitual en $A B C$, contiene críticas a la labor del Gobierno central, con Sánchez de eje central de esta censura. La portada aporta indicios claros sobre su preferencia ideológica (Davara et al., 2004).

El protagonismo de la política como sujeto informativo, habitual en la prensa, se diluye, se mantiene la preeminencia de las figuras políticas (Sánchez, Gobierno central y autonómicos) para dar cuenta de informaciones de carácter social, como las medidas de confinamiento o datos sanitarios referentes a la pandemia. Hay que sumar la presencia de la policía y el ejército, y también el Rey, para contemplar en su conjunto la exposición que los poderes del Estado tienen en la prensa en esta crisis del Covid-19. El recurso sistemático en los medios de frames visuales para complementar la información textual (Muñiz et al., 2008) no se ha confirmado totalmente en este trabajo, aunque sí existe una correlación habitual entre ambos formatos y sus enfoques.

El ascenso de la presencia mediática de nuevos actores informativos de carácter alternativo - ONG, sociedad civil, expertos, etc.- se han confirmado en estudios diacrónicos de primeras páginas de diarios españoles (López-Rabadán y CaseroRipollés, 2012). Este trabajo reafirma esa idea, en tanto que la sociedad civil es la protagonista principal, así como los expertos.

El discurso centrado en las expresiones beligerantes y la dimensión argumentativa revela que la presentación de las portadas, sus protagonistas o los recursos estilísticos son un elemento clave para captar la atención de los lectores (Davara et al., 2004).

Ha quedado demostrado que el lenguaje bélico, propio de las crónicas deportivas (Barrero, 2007), está presente en las noticias del Covid-19. El uso de metáforas bélicas por parte de los políticos en los medios de comunicación puede empujar a la confrontación social, mientras que entender la situación de pandemia como un camino que todos debemos recorrer ayudaría a generar sentimientos solidarios (Ostolaza, 2020). El lenguaje bélico es un recurso que aporta color y dramatismo que en realidad no requiere el género de la noticia. En las informaciones sobre el coronavirus, el lenguaje bélico se entiende como forma de militarizar a la sociedad para que actúe obediente y uniforme en el cumplimiento de las medidas de confinamiento, en una forma de domesticación pacífica. En este contexto bélico aparece la figura del héroe, representada en los médicos y los sanitarios, y en menor grado en las policías y los militares. 
Análisis de los titulares y las fotografías de portada en España en el contexto de la crisis del coronavirus: protagonistas, frames y lenguaje bélico

El peso de las soft news es relativo en las primeras páginas, una característica histórica de las portadas (López-Rabadán y Casero-Ripollés, 2012). Las cabeceras refieren a las duras consecuencias de la pandemia. Los resultados también nos indican que la prensa recurre a los marcos de imágenes para reforzar el enfoque de los titulares, aunque hay ejemplos en sentido contrario, con fotos que relajan la tensión de los titulares duros durante la pandemia. La presencia de la sociedad civil como actor principal en las fotografías supone un contrapeso a las hard news de los titulares. No obstante, este protagonismo se mitiga con las imágenes de la acción policial o militar, e incluso la figura de políticos, que habitualmente ocupan este espacio preferente. La pandemia ha permitido que la Policía y el Ejército se presenten como estrechos colaboradores de la ciudadanía, estableciendo el control que requiere una situación de alerta y mostrando una actitud proactiva dentro de una estrategia en contra de la expansión del coronavirus. La figura del Rey es el máximo exponente de esta representación metafórica, especialmente cuando aparece ataviado con el traje militar. En los casos en los que Felipe II aparece con guantes y mascarillas la figura evoca la necesidad del cumplimiento de las reglas impuestas, desde la máxima autoridad hasta los civiles de a pie.

En esa puesta en escena que supone la portada, las imágenes del Rey de España y del presidente del Gobierno español con mascarilla se encuadran en los iconos que mejor representan la estética de esta pandemia, junto a las multipantallas (Carrión, 2020). En contra de la percepción que emite la pantalla de plasma, el mosaico trasmite voluntad de diálogo, interacción frente a la distancia impuesta por el confinamiento, y jerarquía. El mosaico aparece en el primer capítulo de la primera serie sobre el Covid19 emitida en televisión, por Netflix, como muestra de su impacto mediático.

Pese a su carácter exploratorio e inicial, estos hallazgos revelan la existencia de una influencia importante del Covid-19 sobre el sistema mediático, que abarca la mayoría de las portadas de los diarios en papel. Se comprueba el papel del periodismo como actor que ejerce la construcción simbólica de los acontecimientos, en alianza, pero también en tensión, con el sistema político, para homogeneizar los discursos y de esta forma mantener en la sociedad una cohesión imprescindible para la convivencia.

\section{REFERENCIAS}

Acosta, R. (2013). Producción y circulación de la noticia: el newsmaking. Chasqui. Revista Internacional de Comunicación, (123), 64-75.

Álvarez Berastegi, A., Gurrutxaga, G. y Goikoetxea, U. (2019). El efecto péndulo de la transición digital. Un estudio cualitativo sobre medios en euskera y en catalán. Estudios Sobre El Mensaje Periodístico, 25(2), 621-637. doi: https://doi.org/10.5209/esmp.64791

Armentia, J. I. y Caminos, J. (2009). Redacción informativa. Barcelona. Ariel. 
Análisis de los titulares y las fotografías de portada en España en el contexto de la crisis del coronavirus: protagonistas, frames y lenguaje bélico

Aruguete, N. (2009). Estableciendo la agenda. Los orígenes y la evolución de la teoría de la agenda-setting. Ecos de la Comunicación, 2(2), 11-38. https://bit.ly/3fQaMFc

Barrero, J. (2007). El tratamiento de la violencia en el fútbol por la prensa deportiva. Doxa Comunicación, (5), 141-157. https://doi.org/10.31921/doxacom.n5a7

Borrat, H. El periódico, actor político. Barcelona. Gustavo Gili.

Carr, N. (2011). Superficiales. ¿Qué está haciendo internet con nuestras mentes? Madrid, Taurus.

Carrión, J. (2020). La estética de la pandemia. Blog. Consultado el 22 de abril de 2020. https://nyti.ms/3fH1rPT

Casero-Ripollés, A. (2020). Impact of Covid-19 on the media system. Communicative and democratic consequences of news consumption during the outbreak. El profesional de la información, 29(2), e290223. doi: 10.3145/epi.2020.mar.23

Castromil, A. (2012). Negativismo mediático y campaña electoral en las Elecciones. Revista Española de Investigaciones Sociológicas. (139), 163-174. doi: $\underline{10.5477 / \text { cis/reis.139.163 }}$

Cervantes, C. (1996). Construcción primaria del acontecer y planeación de la cobertura informativa: propuesta metodológica para su estudio. Comunicación y Sociedad, (28), 49-82. https://bit.ly/2BsXSxd

Cinelli, M., Quattrociocchi, W., Galeazzi, A., Valensise, C. M., Brugnoli, E., Schmidt, A. L., Zola, P., Zollo, F. y Scala, A., (2020). The Covid-19 social media infodemic. Consultado el 21 de abril de 2020. https://arxiv.org/pdf/2003.05004.pdf

Davara, J., López, P., Martínez-Fresneda, H. y Sánchez-Rodríguez, G. (2004). España en portada. Madrid. Fragua.

De Vreese, C. (2005). News Framing: Theory and Typology. Information Design Journal, 13(1), 51-62. doi: 10.1075/idjdd.13.1.06vre

Edelman, R. (2020). Brand trust and the coronavirus pandemic. Consultado el 19 de abril de 2020. https://bit.ly/3dIUWKI

Entman, R. (1993). Framing: Toward Clarification of a Factured Paradigm. Journal of Communication, 43(4), 51-58. doi: 10.1111/j.1460-2466.1993.tb01304.x

Gaitán, J. A. y Piñuel, J. L. (1998). Técnicas de investigación en comunicación social. Madrid. Síntesis. 
Análisis de los titulares y las fotografías de portada en España en el contexto de la crisis del coronavirus: protagonistas, frames y lenguaje bélico

Goffman, E. (2006). Frame Analysis. Los marcos de la experiencia. Madrid, Centro de Investigaciones Sociológicas.

Igartua, J. J., Muñiz, C. y Otero, J. A. (2007). El tratamiento informativo de la inmigración en los medios de comunicación españoles. Un análisis de contenido desde la Teoría del Framing. Estudios sobre el Mensaje Periodístico, (13), 91-110. https://bit.ly/2MpbaNm

Krippendorf, K. (1990). Metodología de análisis de contenido. Teoría y Práctica. Barcelona, Paidós.

Lázaro-Rodríguez, P. y Herrera-Viedma, E. (2020). Noticias sobre Covid-19 y 2019nCoV en medios de comunicación de España: el papel de los medios digitales en tiempos de confinamiento. El profesional de la información, 29(3), e290302. doi: https://doi.org/10.3145/epi.2020.may.02

López-Rabadán, P. y Casero-Ripollés, A. (2012). La evolución de la agenda mediática española (1980-2010). Un análisis longitudinal de la portada de la prensa de referencia. Revista Latina de comunicación, (67), 470-493. doi: 10.4185/RLCS-2012$\underline{964}$

Lubens, P. (2015). Journalists and public health professionals: Challenges of a symbiotic relationship. Disaster medicine and public health preparedness, 9(1), 5963. doi: $\underline{10.1017 / \mathrm{dmp} .2014 .127}$

Luengo, O. (2014). Twitter vs medios tradicionales. ¿Ha implicado Twitter un espacio ciudadano real de intercambio de información? In: Cotarelo, Ramón; Olmeda, JoséAntonio (eds.). La democracia del siglo XXI. Política, medios de comunicación, internet y redes sociales (pp. 409-428). Madrid. Centro de Estudios Políticos y Constitucionales.

Marín, F., Armentia, J. I. y Caminos, J. (2014). El anuncio del cese de la actividad de ETA en los diarios españoles: análisis de las portadas desde la teoría del framing. Trípodos, 1(34), 173-200. https://bit.ly/3cpLLO3

Martínez, J. (2018). Noam Chomsky: La gente ya no cree en los hechos. El País. Consultado el 2 de febrero de 2019. https://bit.ly/2Z3wKhS

McCombs, M. y Evatt, D. (1995). Los temas y los aspectos. Explorando una nueva dimensión de agenda setting. Comunicación y Sociedad, 8(1), 7-32. https://bit.ly/3dnSedP

Messaris, P. y Abraham L. (2001). The role of images in framing news stories. In: Reese, S. D.; Gandy, O. H.; Grant, A. E. (eds.). Framing public life. Perspectives on media and our understanding of the social world.Mahwah, (pp. 215-226). NJ: Lawrence Erlbaum Associates. 
Análisis de los titulares y las fotografías de portada en España en el contexto de la crisis del coronavirus: protagonistas, frames y lenguaje bélico

Moragas, M. (1985). Sociología de la comunicación de masas. Barcelona. Gustavo Gili.

Muñiz, C., Igartua, J. J., Fuente, M. y Otero, J. A. (2008). Imágenes periodísticas de la inmigración. Aportaciones metodológicas al estudio de la comunicación visual. Análisi, (37), 31-48. https://bit.ly/2WDOSgV

Ostolaza, P. (2020). Herritarrak soldadutzat hartu izanak gaitzespena eragin du. Berria. https://bit.ly/35U9m7U

Reese, S. D. (2007). The Framing Project: A Bridging Model for Media Research. Journal of Communication, 57(1), 148-154. doi: 10.1111/j.1460-2466.2006.00334.x

Scheufele, B. (2005). Framing-effects approach: A theoretical and methodological critique. The European Journal of Communication Research, 29(4), 401-428. doi: 10.1515/comm.2004.29.4.401

Shoemaker, P. y Reese, S. (2013). Mediating the message in the 21st century: a media sociology perspective. Londres. Routledge.

Rodríguez-Andrés, R. (2011). La efectividad del uso del miedo como factor persuasivo en la comunicación de riesgos en las crisis sanitarias. Revista de Comunicación y Salud, 1(2), 33- 46. https://bit.ly/3dSYNES

Tankard, J. (2001). The empirical approach to the study of media framing. In: Reese, S. D.; Gandy, O. H.; y Grant, A. E. (eds.). Framing public life. Perspectives on media and our understanding of the social world, (pp. 95-105). Mahwawah, NJ, Lawrence Erlbaum.

Torres-Salinas, D. (2020). Ritmo de crecimiento diario de la producción científica sobre Covid-19. Análisis en bases de datos y repositorios en acceso abierto. El profesional de la información, 29(2), e290215. doi: 10.3145/epi.2020.mar.15

Tuchman, G. (1983). La producción de la noticia. Barcelona, Gustavo Gili.

Valkenburg, P., Semetko, H. y De Vreese, C. (1999). The effects of news frames on reader's thoughts and recall. Communication Research, (26), 550-569. doi: $\underline{10.1177 / 009365099026005002}$

Van Dijk, T. y Kintsch, W. (1983). Strategies of Discourse Comprehension. New Cork, Academia Press.

Van Dijk, T. (2016). Análisis crítico del discurso. Revista Austral de Ciencias Sociales, (30), 203-222. doi: 10.4206/rev.austral.cienc.soc.2016.n30-10

Vega, L. (2016). Introducción a la teoría de la argumentación. Lima. Palestra.

Revista de Comunicación y Salud, 2020, Vol. 10, № 2, pp. 1-23 
Análisis de los titulares y las fotografías de portada en España en el contexto de la crisis del coronavirus: protagonistas, frames y lenguaje bélico

Westlund, O. y Ghersetti, M. (2015). Modelling news media use. Positing and applying the GC/MC model to the analysis of media use in everyday life and crisis situations. Journalism studies, 16(2), 133-151. doi: $\underline{10.1080 / 1461670 X .2013 .868139}$

Xifra, J. (2020). Comunicación corporativa, relaciones públicas y gestión del riesgo reputacional en tiempos del Covid-19. El profesional de la información, 29(2), e290220. doi: 10.3145/epi.2020.mar.20

Zabaleta, I. (1979). Komunikazioaren ikerkuntzarako metodologia. Bilbao. Udako Euskal Unibertsitatea.

\section{AUTORES}

\section{Jose-Luis Argiñano}

Profesor en la Facultad de Ciencias Sociales y de la Comunicación de la Universidad del País Vasco/Euskal Herriko Unibertsitatea (UPV/EHU). Tras veinte años de experiencia profesional en El Mundo, El País o 20 Minutos, desarrolla su labor docente e investigadora en áreas vinculadas al periodismo especializado y a la comunicación y la seguridad alimentaria. Forma parte del Grupo de Investigación Medialker (referencia GIU16/08). Participa en el proyecto "Seguridad Alimentaria y Cibermedios: Temáticas, nuevas fuentes y servicios", financiado en la convocatoria 2017 de los proyectos de I+D+I del programa estatal de Investigación, Desarrollo e Innovación orientada a los retos de la sociedad promovido por el Ministerio de Economía, Industria y Competitividad.

Orcid ID: https://orcid.org/0000-0001-8191-6309

Google Scholar: https://scholar.google.es/citations?user=TyVNEx4AAAAJ\&hl=es

\section{Udane Goikoetxea}

Es periodista y profesora del Departamento de Periodismo de la Universidad del País Vasco / Euskal Herriko Unibertsitatea (UPV/EHU). Realizó un Máster en Formación del profesorado y otro en Comunicación Social. Cuenta con una trayectoria de 15 años como periodista en radio y televisión. Durante su trayectoria académica ha asistido a numerosos congresos y ha publicado en revistas nacionales e internacionales. Forma parte del grupo de investigación HGH donde colabora en proyectos de investigación relacionados con periodismo de calidad y periodismo reposado, entre otros. También ha realizado trabajos de investigación sobre la lectura como: Los criterios para evaluar la lectura en voz alta en Vizcaya y Materiales para trabajar en la lectura en voz alta en Vizcaya.

Orcid ID: https://orcid.org/0000-0002-9844-5221

Google Scholar: https://scholar.google.es/citations?user=CDHVGwwAAAAJ\&hl=es 